Journal for ImmunoTherapy of Cancer

\section{Regulatory T-cell depletion in the setting of autologous stem cell transplantation for multiple myeloma: pilot study}

\author{
Benjamin A Derman (D) , ${ }^{1}$ Yuanyuan Zha, ${ }^{1}$ Todd M Zimmerman, ${ }^{2}$ Rebecca Malloy, ${ }^{1}$ \\ Andrzej Jakubowiak, ${ }^{1}$ Michael R Bishop, ${ }^{1}$ Justin Kline ${ }^{1}$
}

To cite: Derman BA, Zha Y, Zimmerman TM, et al. Regulatory T-cell depletion in the setting of autologous stem cell transplantation for multiple myeloma: pilot study. Journal for ImmunoTherapy of Cancer 2020;8:e000286. doi:10.1136/ jitc-2019-000286

MRB and JK are joint senior authors.

Accepted 05 December 2019

Check for updates

(C) Author(s) (or their employer(s)) 2020. Re-use permitted under CC BY-NC. No commercial re-use. See rights and permissions. Published by BMJ.

${ }^{1}$ Section of Hematology/ Oncology, University of Chicago Medical Center, Chicago, Illinois, USA

${ }^{2}$ BeiGene, San Mateo, CA, United States

Correspondence to Dr Benjamin A Derman; bderman@medicine.bsd. uchicago.edu

\section{ABSTRACT}

Background Progression after high-dose melphalan with autologous stem cell transplantation (ASCT) in multiple myeloma (MM) may be due in part to immune dysfunction. Regulatory T (Treg) cells reconstitute rapidly after ASCT and inhibit immune responses against myeloma cells. Methods We performed a randomized study to evaluate two methods of Treg depletion in patients with MM undergoing ASCT. No Treg depletion was performed in the control ASCT arm. An anti-CD25 monoclonal antibody (basiliximab $20 \mathrm{mg}$ IV) was administered on day +1 postASCT in the in vivo Treg depletion (IVTRD) arm. Tregs were depleted from autologous stem cell (ASC) grafts with antiCD25 microbeads and the CliniMACS device in the ex vivo Treg depletion (EVTRD) arm.

Results Fifteen patients were enrolled, five in each arm. The conditioning regimen was melphalan $200 \mathrm{mg} / \mathrm{m}^{2}$. Primary objectives included assessments of efficiency of IVTRD/EVTRD, kinetics of Treg depletion and recovery following ASCT, and safety. EVTRD removed $90 \%$ of $\mathrm{CD} 4^{+} \mathrm{CD} 25^{+}$cells from ASC grafts. IVTRD and EVTRD led to reductions in Treg frequency between days +7 and +90 post-transplant compared with the control $(p=0.007$ and $p<0.001$, respectively).

Conclusions IVTRD and EVTRD are feasible and significantly reduce and delay Treg recovery post-ASCT for MM, and serve as a platform for using post-transplant immunotherapies to improve post-ASCT outcomes. Trial registration number NCT01526096.

\section{BACKGROUND}

High-dose melphalan followed by autologous stem cell transplantation (ASCT) is a mainstay of intensification therapy for eligible patients with multiple myeloma (MM). When using bortezomib, lenalidomide, and dexamethasone as part of frontline therapy in the IFM-2009 study, early ASCT was shown to increase the depth of response and median progression-free survival (PFS) (50 vs 36 months, $\mathrm{p}<0.001)$ as compared with a strategy of delayed ASCT; at 4 years of follow-up, overall survival (OS) was similar between the two arms. ${ }^{1}$ These findings are in keeping with several other randomized phase III trials comparing ASCT to conventional chemotherapy prior to the inclusion of contemporary induction agents. ${ }^{2-7}$ In total, this indicates that even with modern induction and maintenance therapy, median PFS for post-transplant patients with $\mathrm{MM}$ is still under 5 years, which may be due to persistent minimal residual disease (MRD) following ASCT.

Immunotherapy is a non-cross-resistant therapeutic approach that may be most effective in this MRD-positive state. Regulatory $\mathrm{T}$ (Treg) cells represent a small but important subset of naturally suppressive $\mathrm{CD} 4^{+} \mathrm{T}$ cells $\left(\mathrm{CD} 4^{+} \mathrm{CD} 25^{+} \mathrm{FoxP}^{+}\right)$that inhibit anticancer immune responses, thereby promoting tumor progression. 9 High-dose chemotherapy followed by ASCT leads to protracted lymphopenia, which is then followed by expansion of reinfused $\mathrm{T}$ cells in the autologous stem cell (ASC) graft. ${ }^{10}$ Immune reconstitution of Tregs occurs as early as 2 weeks after ASCT, and Tregs remain elevated at day +90 before returning to normal levels approximately 6 months post-ASCT. ${ }^{11}$ Though the thymus represents the source for endogenous longlived Treg cells, Treg expansion post-ASCT is likely coming from infused graft rather than the thymus. This suggests that there may be a short window in the post-ASCT period where Treg depletion may enhance the antitumor immune response in the MRD-positive state that exists following ASCT.

Cancers activate escape pathways in order to escape immune surveillance. Expansion and accumulation of Treg cells in the tumor microenvironment is one major immune evasion mechanism activated across human cancers, and MM is no exception. ${ }^{13-15}$ Tregs appear to play a significant role in MM progression, and Treg depletion in murine 
A

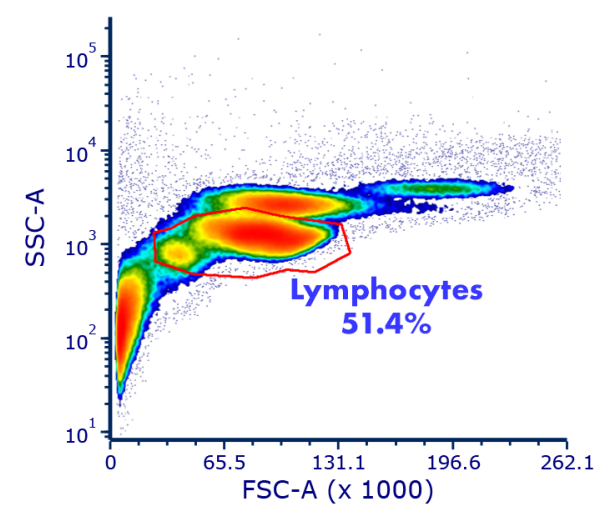

C

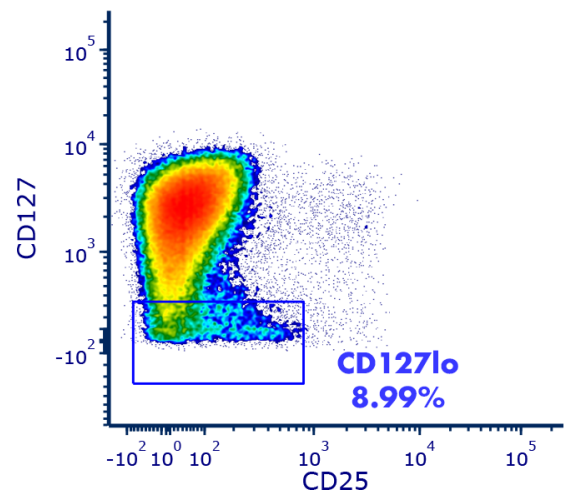

B

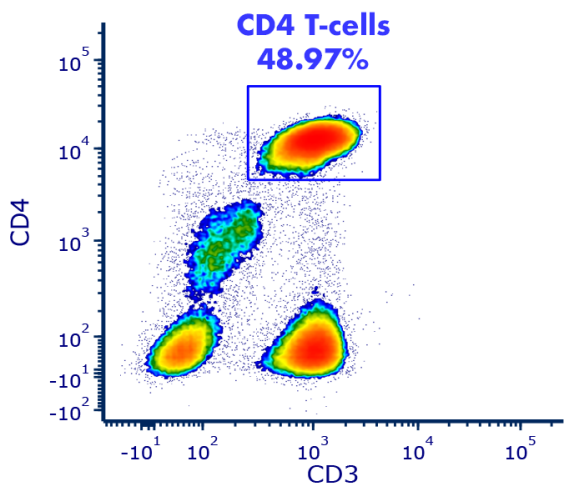

D

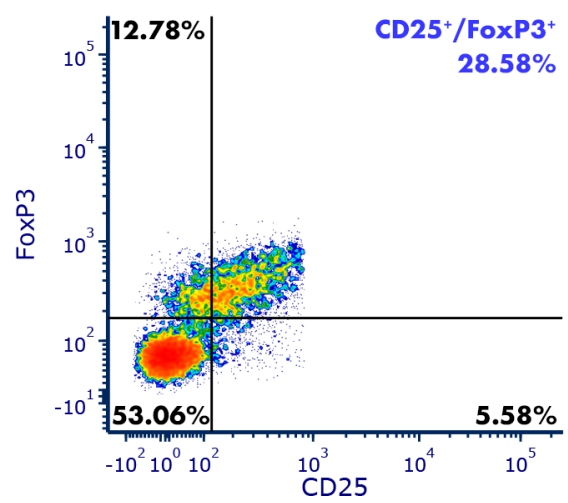

Figure 1 Flow cytometry gating strategy to identify peripheral blood Tregs. (A) Lymphocyte population was identified by forward scatter (FSC)/side scatter (SSC) gating. (B) Frequency of CD3 ${ }^{+} \mathrm{CD} 4^{+} \mathrm{T}$ cells. (C) CD4 ${ }^{+} \mathrm{CD} 127^{\mathrm{lo}} \mathrm{T}$ cells. (D) After gating on $\mathrm{CD} 4^{+} \mathrm{CD} 127^{\mathrm{lo}}$ cells, Treg cells were identified as $\mathrm{CD}^{+} 5^{+}$FoxP3 ${ }^{+}$cells. Flow cytometry analysis was performed using MACSQuant analyzer (Miltenyi Biotec).

models has been effective in inhibiting MM progression through enhancing antimyeloma immune responses. ${ }^{16-18}$ However, there is a paucity of data on the ability to deplete Tregs and its efficacy in humans with MM.

To address the hypothesis that early Treg depletion can be accomplished in the post-ASCT MM setting, we conducted a randomized pilot study to evaluate the feasibility and efficacy of in vivo Treg depletion (IVTRD) and ex vivo Treg depletion (EVTRD) in patients with MM undergoing ASCT.

\section{METHODS}

\section{Criteria for enrollment}

Transplant-eligible patients aged 21-70 years with symptomatic, newly diagnosed MM having undergone induction therapy were eligible for this study. Additional inclusion criteria were Eastern Cooperative Oncology Group (ECOG) performance status of $\leq 2$, HIV and hepatitis $\mathrm{B} / \mathrm{C}$ serology-negative, without cardiac or pulmonary dysfunction (left ventricular ejection fraction $>50 \%$, forced expiratory volume in one second $\left(\mathrm{FEV}_{1}\right)>60 \%$, and diffusing capacity of lung for carbon monoxide (DLCO) $>60 \%$ predicted), bilirubin $<2 \times$ Upper Limit of Normal, and estimated glomerular filtration rate $>40 \mathrm{~mL} /$ $\min / 1.73 \mathrm{~m}^{2}$. Exclusion criteria were pregnant or nursing women, use of systemic immunosuppressive medications, psychiatric illness, and active autoimmune disease (not including type 1 diabetes mellitus or autoimmune hypothyroidism). The protocol was registered as a randomized trial with ClinicalTrials.gov.

\section{Trial design and treatment}

Patients were enrolled from March 2013 through July 2017 and randomly assigned to one of three treatment groups: (1) no Treg depletion ('control ASCT arm'), (2) IVTRD with the anti-CD25 monoclonal antibody basiliximab ('IVTRD arm'), and (3) EVTRD of ASC grafts using CD25 microbeads ('EVTRD arm').

Peripheral blood stem cells were mobilized using filgrastim and plerixafor in all patients. The conditioning regimen consisted of melphalan $200 \mathrm{mg} / \mathrm{m}^{2}$, which was administered as $100 \mathrm{mg} / \mathrm{m}^{2}$ on days -3 and -2 prior to stem cell infusion on day 0. In the EVTRD arm, ASC grafts were depleted of Tregs using anti-CD25 microbeads and the CliniMACS device (Miltenyi Biotec, $\mathrm{GmbH}$ ) prior to infusion. Basiliximab $(20 \mathrm{mg})$, an anti-CD25 monoclonal antibody, was administered intravenously on day +1 to patients in the IVTRD arm. Patients were allowed to receive post-ASCT consolidation and/or maintenance 

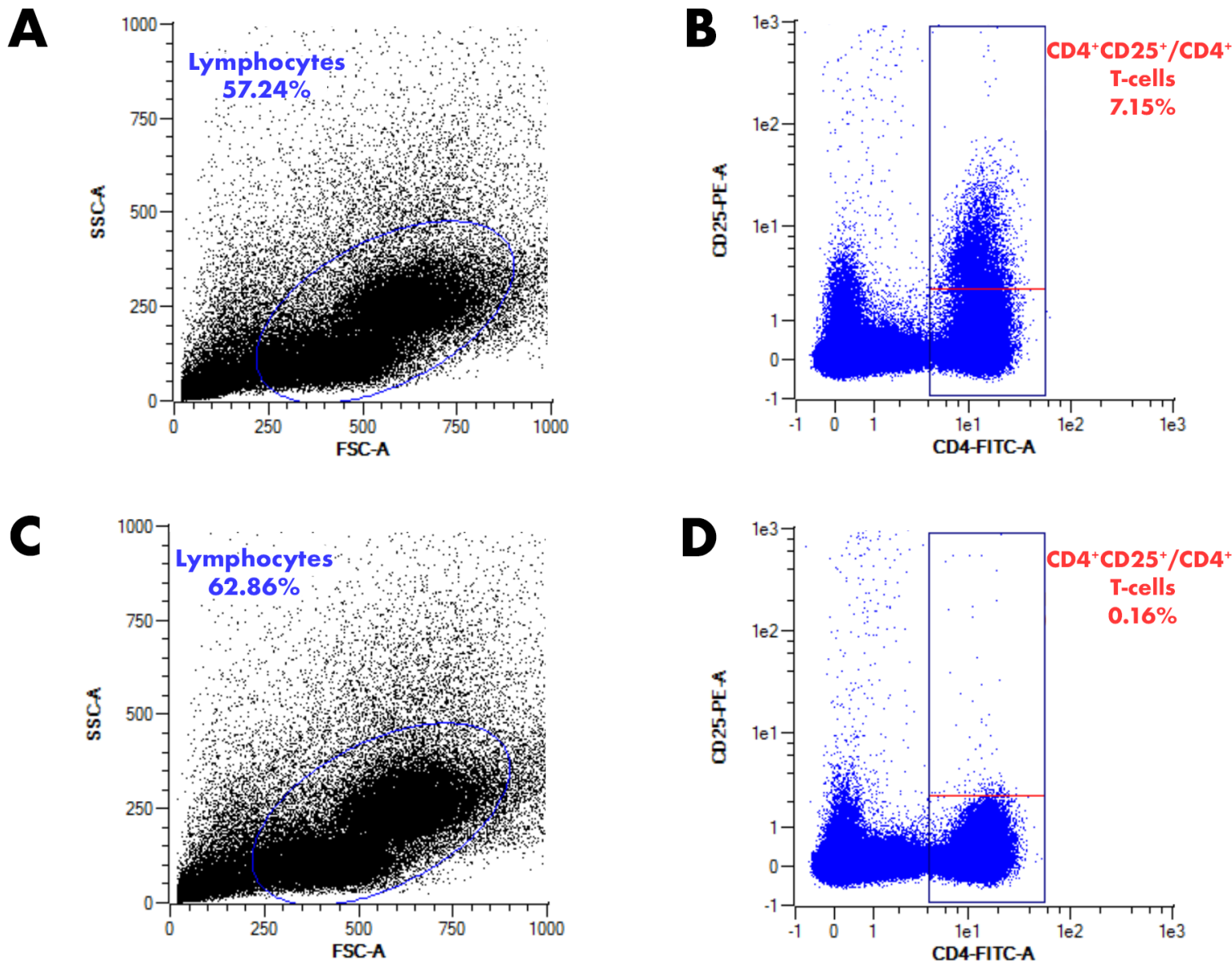

Figure 2 EVTRD from an autologous stem cell graft using anti-CD25 microbeads and the CliniMACS device. The predepletion lymphocyte population is identified in (A), and relative $\mathrm{CD} 4^{+} \mathrm{CD} 25^{+} / \mathrm{CD} 4^{+} \mathrm{T}$ cells are identified in (B). Postdepletion lymphocyte population and relative $\mathrm{CD} 4^{+} \mathrm{CD} 25^{+} / \mathrm{CD} 4^{+} \mathrm{T}$ cells are identified in (C) and (D), respectively. in this example, the relative efficiency of EVTRD was approximately 98\%. Flow cytometry analysis was performed using MACSQuant analyzer (Miltenyi Biotec). EVTRD, ex vivo Treg depletion; FITC, fluorescein isothiocyanate; FSC, forward scatter; SSC, side scatter.

therapy starting at day +100 at the discretion of the treating physician.

\section{Endpoints}

The primary endpoints were efficiency of Treg depletion in the IVTRD and EVTRD arms, post-transplant kinetics of Treg depletion and recovery up to day +180 , and clinical toxicities of these three arms. Secondary endpoints were the rate and timing of neutrophil and platelet engraftment, and disease response.

\section{Assessments}

Peripheral blood Tregs were identified as $\mathrm{CD} 4^{+} \mathrm{CD} 25^{+-}$ FoxP $3^{+} \mathrm{CD} 127^{\text {lo }}$ cells by flow cytometry of peripheral blood (figure 1) and as $\mathrm{CD} 4^{+} \mathrm{CD} 25^{+}$cells in ASC grafts (figure 2), as described previously. ${ }^{19} 20$ Peripheral blood samples were collected at days $-3,0,+7,+14,+21,+28$, $+42,+60$ and +90 post-ASCT as prespecified timepoints for assessing Treg depletion. Day +180 was a prespecified timepoint, but only one patient had peripheral blood drawn at this timepoint due to low adherence, as $13 / 14$ patients went on maintenance therapy prior to this timepoint, which was thought to likely confound results.
Other T-cell subsets, such as central memory or effector memory T cells, were not analyzed.

Best treatment response and disease progression were evaluated according to the International Myeloma Working Group (IMWG) consensus criteria for response and MRD assessment in MM. ${ }^{21}$ MRD was assessed using multiparametric flow cytometry at a depth of at least $10^{-4}$ (range $10^{-4}$ to $10^{-5}$ ). PFS was defined as the time from the date of ASC infusion until the first documentation of disease progression or death from any cause. OS was defined as the time from the date of ASC infusion until death from any cause.

Continuous variables were compared using the MannWhitney U-test and the independent samples t-test for non-normally and normally distributed data, respectively. Categorical variables were compared using the Fisher's exact test. A two-way analysis of variance (ANOVA) was performed to compare the main effects of treatment arm and post-transplant time and the interaction effect between treatment arm and post-transplant time on Treg frequency. Treatment arms included three groups (control ASCT, IVTRD, and EVTRD); post-transplant 


\begin{tabular}{|c|c|c|c|}
\hline & $\begin{array}{l}\text { Control } \\
\text { ASCT } \\
(n=5)\end{array}$ & $\begin{array}{l}\text { IVTRD } \\
(n=4)\end{array}$ & $\begin{array}{l}\text { EVTRD } \\
(n=5)\end{array}$ \\
\hline Age (years), median & 60.3 & 64.0 & 57.1 \\
\hline Male gender, n (\%) & $2(40)$ & $3(75)$ & $2(40)$ \\
\hline \multicolumn{4}{|l|}{ Race/ethnicity, n (\%) } \\
\hline Caucasian & $4(80)$ & $4(100)$ & $1(20)$ \\
\hline Black & $1(20)$ & $0(0)$ & $3(60)$ \\
\hline Hispanic/Latino & $0(0)$ & $0(0)$ & $1(20)$ \\
\hline ISS stage, median & 1 & 1 & 1 \\
\hline 1 & 3 & 3 & 3 \\
\hline 2 & 1 & 1 & 2 \\
\hline 3 & 1 & 0 & 0 \\
\hline $\begin{array}{l}\text { High-risk cytogenetics, } \\
\text { n (\%) }\end{array}$ & $2(40)$ & $4(100)$ & $1(20)^{*}$ \\
\hline
\end{tabular}

Induction therapy, $\mathrm{n}$

(\%)

\begin{tabular}{|llll|}
\hline $\mathrm{RVd}$ & $3(60)$ & $3(75)$ & $5(100)$ \\
\hline $\mathrm{KRd}$ & $1(20)$ & $0(0)$ & $0(0)$ \\
$\mathrm{Rd}$ & $1(20)$ & $0(0)$ & $0(0)$ \\
\hline $\mathrm{Vd}$ & $0(0)$ & $1(25)$ & $0(0)$ \\
$\begin{array}{l}\text { Induction cycles. } \\
\text { median }\end{array}$ & 4 & 4 & 4 \\
\hline
\end{tabular}

Best induction

response, $\mathrm{n}(\%)$

\begin{tabular}{llll}
\hline PR & $3(60)$ & $1(25)$ & $3(60)$ \\
\hline VGPR & $1(20)$ & $1(25)$ & $1(20)$ \\
\hline CR & $0(0)$ & $1(25)$ & $0(0)$ \\
SCR & $1(20)$ & $1(25)$ & $1(20)$ \\
$\begin{array}{l}\text { Stem cell dose } \\
\left(\mathrm{CD}^{+} \times 14^{6} / \mathrm{kg}\right),\end{array}$ & $4.6(2.4-$ & $2.9(2.7-$ & $3.5(2.0-$ \\
median (range) & $6.5)$ & $10.8)$ & $5.2)$ \\
\hline
\end{tabular}

${ }^{*} \mathrm{p}<0.05$ compared with the IVTRD arm.

ASCT, autologous stem cell transplant; CR, complete response; EVTRD, exvivo regulatory T-cell depletion;ISS, International Staging System; IVTRD, in vivo regulatory T-cell depletion; KRd, carfilzomib, lenalidomide, and dexamethasone; PR, partial response; Rd, lenalidomide+dexamethasone; RVd, lenalidomide, bortezomib, and dexamethasone; sCR, stringent complete response; Vd, bortezomib+dexamethasone; VGPR, very good partial response.

time consisted of seven timepoints ('day +7 ', 'day +14 ', 'day +21 ', 'day +28 ', 'day +42 ', 'day +60 ' and 'day +90 '). Analyses were performed using STATA software V.15.0. The cut-off date for analysis was January 15, 2019.

\section{RESULTS}

\section{Patient characteristics}

A total of 15 patients were enrolled, 5 in each arm. One patient in the IVTRD arm was removed from study due to mobilization failure, leaving 14 patients available for evaluation.

Baseline patient characteristics are shown in table 1 , and individual patient characteristics and responses are found in table 2. No significant differences in age, gender, race, or International Staging System stage were present among the three arms. Compared with the IVTRD group, the EVTRD arm had fewer patients with high-risk cytogenetics as defined by the IMWG $(1 / 5$ vs $4 / 4, p=0.048)$; the control ASCT arm had two of five patients with high-risk cytogenetics ( $p=$ not significant (NS)). Patients in all three cohorts received a median of 4 cycles of induction therapy, with the majority receiving triplet therapies (bortezomib, lenalidomide and dexamethasone or carfilzomib, lenalidomide, and dexamethasone). All patients achieved at least a partial response prior to ASCT. A very good partial response or better was achieved in two of fie patients in the control ASCT arm, three of four in the IVTRD arm, and two of five in the EVTRD arm ( $\mathrm{p}=\mathrm{NS}$ between groups). The median and range of the infused $\mathrm{CD} 34^{+}$cell dose $\left(\times 10^{6} /\right.$ $\mathrm{kg}$ ) was 4.6 (range 3.16-6.03) in the control ASCT arm, 2.9 (range 2.65-10.76) in the IVTRD arm, and 3.5 (range $1.95-5.16)$ in the EVTRD arm ( $\mathrm{p}=\mathrm{NS}$ between groups).

\section{Efficiency of ex vivo Treg cell depletion}

Prior to ASC graft manipulation, the median relative Treg frequency $\left(\mathrm{CD}^{+} \mathrm{CD} 25^{+} / \mathrm{CD} 4^{+}\right)$was $8.3 \%$ (range $6.8 \%-19.2 \%$ ). Following $\mathrm{CD}_{2} 5^{+}$cell separation from ASC grafts, the median relative Treg frequency was $0.9 \%$ (range $0.1 \%-2.9 \%, \mathrm{p}=0.0049$ ), corresponding to a $90 \%$ depletion of $\mathrm{CD} 4^{+} \mathrm{CD} 25^{+} \mathrm{T}$ cells (figure 3 ).

\section{Kinetics of Treg cell recovery in the post-ASCT setting}

Treg frequencies from peripheral blood patient samples at each point post-ASCT $\left(\mathrm{CD} 4^{+} \mathrm{CD} 25^{+} \mathrm{FoxP}^{+} \mathrm{CD} 127^{\mathrm{lo}}\right.$ / $\mathrm{CD} 4^{+}$) are shown in figure 4 . Treg frequencies in both the IVTRD and EVTRD arm were generally lower than those in the control ASCT arm. A two-way ANOVA was performed to examine the effect of treatment arm and post-transplant time on Treg frequency. Simple main effects analysis revealed that the treatment arm had a significant effect on Treg frequency $(\mathrm{F}(2,45)=8.35$, $\mathrm{p}=0.008)$. The main effect of post-transplant time on Treg frequency was not significant $(\mathrm{F}(6,45)=1.92$, $\mathrm{p}=0.0977)$. The interaction effect of treatment arm and post-transplant time was not significant $(\mathrm{F}(12,45)=0.49$, $\mathrm{p}=0.9115)$. Using the Bonferroni correction as a post hoc exploratory analysis, IVTRD and EVTRD each individually led to significant reductions in Treg frequency between days +7 and +90 post-transplant compared with the control ASCT arm $(\mathrm{p}=0.007$ and $\mathrm{p}<0.001$, respectively). With the control ASCT group as the comparator in a prespecified analysis of individual timepoints, only the EVTRD arm had a significantly lower median Treg frequency at day +21 post-ASCT $(\mathrm{p}=0.025)$.

\section{Patient outcomes}

The median time to neutrophil and platelet engraftment was similar across all three arms (10-11 days). 
Table 2 Individual patient characteristics and responses

\begin{tabular}{|c|c|c|c|c|c|c|c|}
\hline $\begin{array}{l}\text { Patient } \\
\text { number }\end{array}$ & $\begin{array}{l}\text { Age } \\
\text { (years) }\end{array}$ & R-ISS & $\begin{array}{l}\text { Induction } \\
\text { regimen }\end{array}$ & $\begin{array}{l}\text { Pre-ASCT } \\
\text { response }\end{array}$ & $\begin{array}{l}\text { Best post-ASCT } \\
\text { response }\end{array}$ & $\begin{array}{l}\text { Post-ASCT } \\
\text { consolidation }\end{array}$ & $\begin{array}{l}\text { Post-ASCT } \\
\text { maintenance }\end{array}$ \\
\hline \multicolumn{8}{|l|}{ Control } \\
\hline 2 & 50 & 2 & VRd & sCR & MRD-neg sCR & None & $\mathrm{R}$ \\
\hline 3 & 60 & 2 & VRd & PR & PR & $V R d \times 4$ & VRd \\
\hline \multicolumn{8}{|l|}{ IVTRD } \\
\hline 6 & 49 & 2 & VRd & PR & VGPR & None & $\mathrm{R}$ \\
\hline 7 & 62 & 1 & Vd & MRD-neg sCR & sCR & VRd $\times 2$ & $\mathrm{R}$ \\
\hline 8 & 65 & 1 & VRd & VGPR & MRD-neg sCR & $V R d \times 4$ & $\mathrm{R}$ \\
\hline 11 & 46 & 1 & VRd & sCR & sCR & VRd $\times 2$ & $\mathrm{R}$ \\
\hline 12 & 67 & 2 & VRd & PR & MRD-neg sCR & VRd $\times 2$ & $\mathrm{R}$ \\
\hline 13 & 64 & 2 & VRd & VGPR & MRD-neg sCR & $\mathrm{KRd} \times 8$ & $\mathrm{R}$ \\
\hline 14 & 53 & 1 & VRd & PR & MRD-neg sCR & None & $\mathrm{R}$ \\
\hline
\end{tabular}

*Patient declined maintenance therapy.

ASCT, autologous stem cell transplant; CR, complete response; EVTRD, ex vivo Treg depletion; IVTRD, in vivo Treg depletion;KRd, carfilzomib, lenalidomide, and dexamethasone; MRD-neg, minimal residual disease negative; PR, partial response; R, lenalidomide;Rd, lenalidomide+dexamethasone; R-ISS, Revised-International Staging System; sCR, stringent complete response;Vd, bortezomib+dexamethasone; VGPR, very good partial response; VRd, bortezomib, lenalidomide, and dexamethasone .

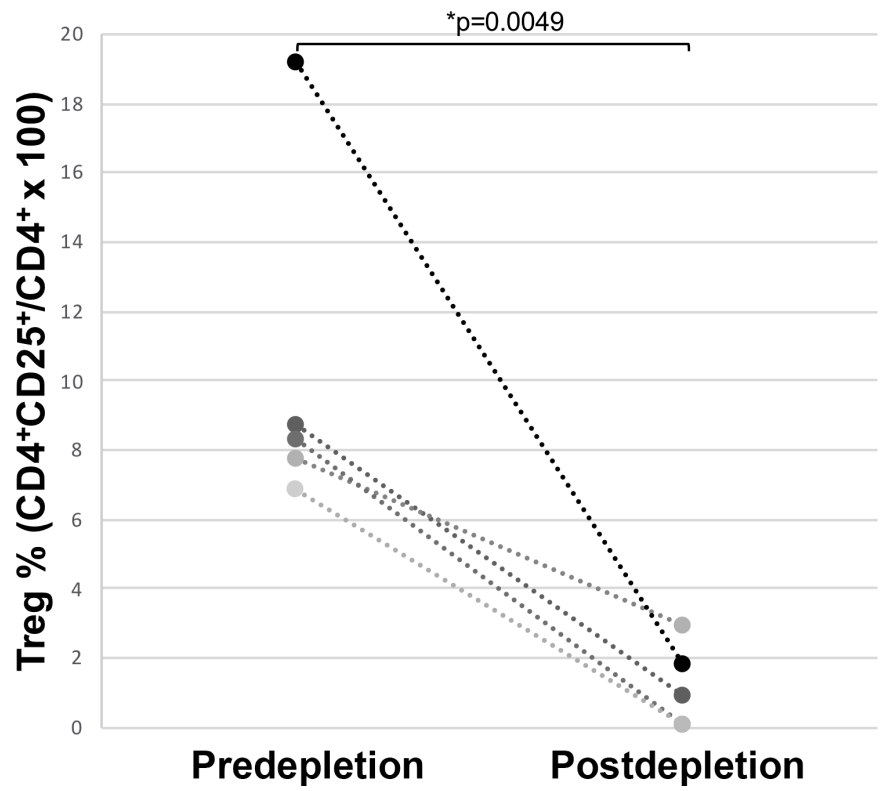

Figure 3 EVTRD from ASC grafts is highly efficient. Frequencies of $\mathrm{CD} 4^{+} \mathrm{CD} 25^{+}$Treg cells in each ASC graft are shown prior to and following the EVTRD procedure $(p=0.0049)$. ASC, autologous stem cell; EVTRD, ex vivo Treg depletion.
Febrile neutropenia occurred in four of five patients in the EVTRD arm, in one of four patients in the IVTRD arm, and two of five patients in the control ASCT arm $(\mathrm{p}=\mathrm{NS})$. Rash occurred in only one patient and involved $77 \%$ body surface area; this patient was in the EVTRD arm and received systemic corticosteroids, which led to prompt resolution of the rash. The Treg frequency at the time of symptoms was $0.4 \%$ compared with $2.4 \%$ prior to ASCT (83.3\% decrease). The autograft for this patient had $98.2 \%$ of Tregs depleted. Diarrhea occurred in one patient in each arm $(p=N S)$. The number of immune-related adverse events was too few to make any firm conclusions between degree of Treg depletion and the event. A complete list of nonhematological adverse events can be found in table 3. Post-ASCT consolidation and maintenance therapy were administered at similar rates across the groups. One patient in the EVTRD arm received a tandem ASCT, and one patient in the control arm did not receive maintenance therapy due to patient preference.

The median follow-up time was 59, 36, and 68 months for the control ASCT, IVTRD, and EVTRD arms, respectively. All five patients in the EVTRD arm achieved a stringent $\mathrm{CR}$, and four of five achieved MRD negativity by flow cytometry (depth $10^{-4}$ to $10^{-5}$ ). In the IVTRD arm, three 


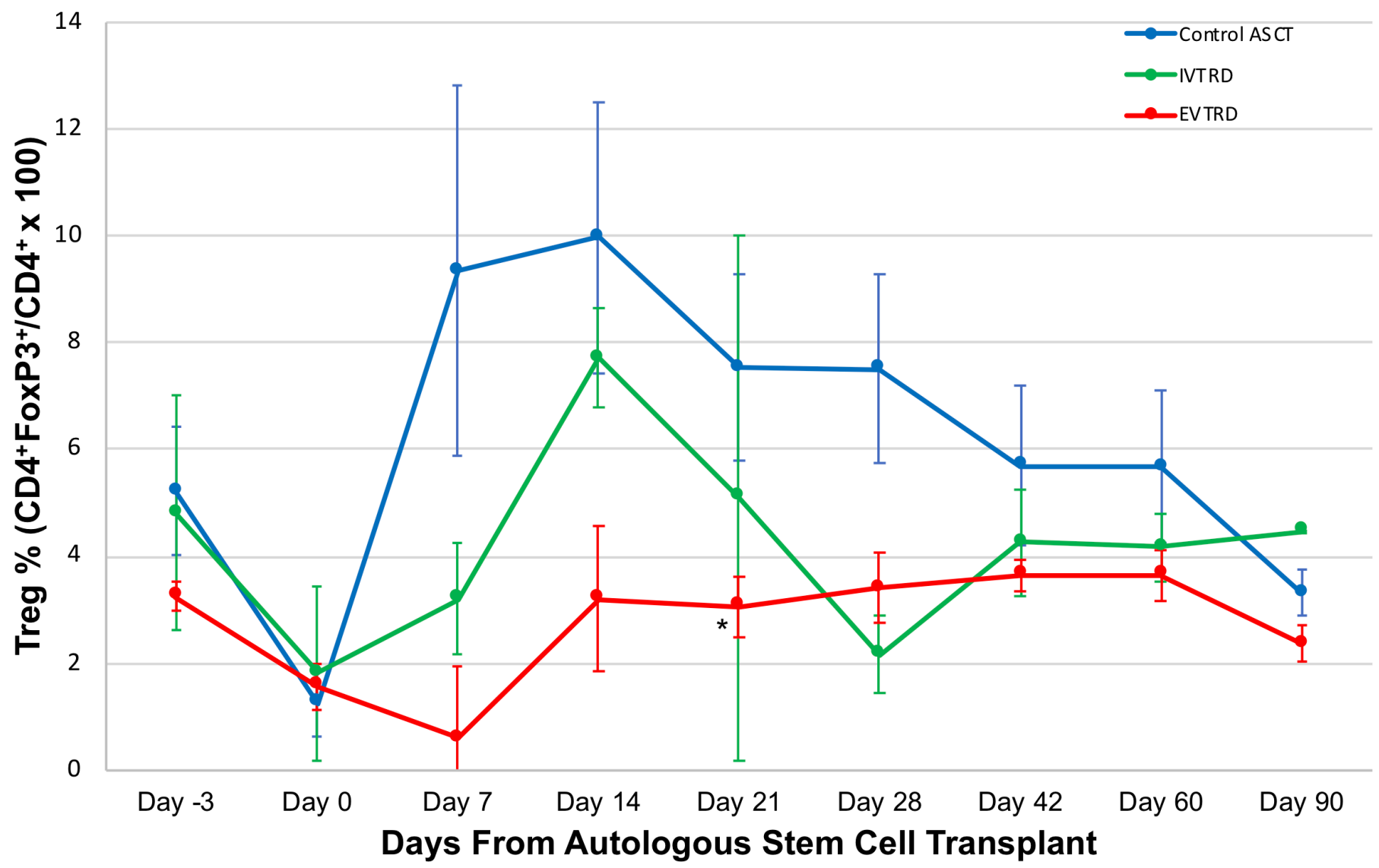

Figure 4 Kinetics of Treg cell depletion and recovery following IVTRD and EVTRD. Median Treg frequencies by treatment arm at the indicated timepoints are shown. The asterisk $\left(^{*}\right)$ indicates $\mathrm{p}=0.025$ for comparison of median Treg cell frequencies in the EVTRD versus control arm at day +21 . Color-coded error bars represent the SE of the mean. ASCT, autologous stem cell transplantation; EVTRD, ex vivo Treg depletion; IVTRD, in vivo Treg depletion.

of four patients achieved an sCR (one was MRD-negative). In the control ASCT arm, three of five patients achieved a sCR with two MRD-negative responses (table 4).

Disease relapse occurred in five patients (two in the control ASCT arm, two in the IVTRD arm, and one in the EVTRD arm). Death occurred in two patients, ultimately due to disease progression: one in the control ASCT arm due to liver failure and one in the IVTRD arm due to metabolic encephalopathy. There were late effects deemed unrelated to study treatment. The 3-year PFS rate was $80 \%$ in the control ASCT arm and $100 \%$ in both the IVTRD and EVTRD arms; the 3-year OS rate was $100 \%$ in all arms. One patient in the EVTRD arm developed therapy-related acute myeloid leukemia.

\section{DISCUSSION}

Inhibiting Treg cell recovery following ASCT in MM is a unique immunotherapeutic approach to potentially enhance MM-specific immune responses in the MRDpositive state. Previous data have suggested that Tregs not only reconstitute early following ASC infusion but also appear to expand in the early post-ASCT period and return to normal levels by 6 months. ${ }^{11}{ }^{12}$ Indeed, this points to a narrow window in the post-ASCT period when Treg depletion may be effective in enhancing antitumor immune responses. Despite the success in Treg depletion in murine models, there has been only one prior study using denileukin difitox to accomplish the same in humans and was closed after enrollment of only two patients due to drug discontinuation by the manufacturer. Mogamulizumab, an anti-CC4 monoclonal antibody, appears to reduce CCR $4^{+}$Treg cells in cutaneous T-cell lymphoma but has not yet been proven in the setting of MM..$^{22} 23$

Our results clearly demonstrate that both EVTRD of ASC grafts and IVTRD using basiliximab are efficient and feasible in patients with MM and importantly lead to significant reductions in Tregs in the early postASCT period in MM. In an exploratory analysis of Treg frequencies between days +7 and +90 , post-ASCT Tregs were significantly reduced in the IVTRD and EVTRD arms compared with the control arm. This was achieved without negatively impacting engraftment, and without significant autoimmune complications, such as the development of autologous graft-versus-host disease.

While the EVTRD of ASC grafts was feasible and effective at reducing the numbers of Tregs in the early posttransplant period, it is unknown how efficient basiliximab at the dose administered was with respect to IVTRD in the context of this study. The half-life of basiliximab is 
Table 3 Non-hematological adverse events

\begin{tabular}{|c|c|c|c|c|c|c|}
\hline \multirow[b]{2}{*}{ Event } & \multicolumn{2}{|c|}{$\begin{array}{l}\text { Control ASCT } \\
(n=5)\end{array}$} & \multicolumn{2}{|c|}{$\begin{array}{l}\text { IVTRD ASCT } \\
(n=4)\end{array}$} & \multicolumn{2}{|c|}{$\begin{array}{l}\text { EVTRD ASCT } \\
(n=5)\end{array}$} \\
\hline & $\begin{array}{l}\text { All } \\
\text { grade }\end{array}$ & $\begin{array}{l}\text { Grade } \\
3 \text { or } 4\end{array}$ & $\begin{array}{l}\text { All } \\
\text { grade }\end{array}$ & $\begin{array}{l}\text { Grade } \\
3 \text { or } 4\end{array}$ & All grade & $\begin{array}{l}\text { Grade } \\
3 \text { or } 4\end{array}$ \\
\hline \multicolumn{7}{|l|}{ Constitutional symptoms } \\
\hline Fatigue & $4(80 \%)$ & $1(20 \%)$ & 0 & 0 & 0 & 0 \\
\hline Fever & $3(60 \%)$ & $2(40 \%)$ & $1(25 \%)$ & $1(25 \%)$ & $4(80 \%)$ & $4(80 \%)$ \\
\hline Pain & $2(40 \%)$ & 0 & $1(25 \%)$ & 0 & $1(20 \%)$ & 0 \\
\hline Weight loss & 0 & 0 & 0 & 0 & $1(20 \%)$ & 0 \\
\hline Malaise & 0 & 0 & 0 & 0 & $1(20 \%)$ & 0 \\
\hline \multicolumn{7}{|l|}{ Gastrointestinal disorders } \\
\hline Nausea & $2(40 \%)$ & 0 & $1(25 \%)$ & 0 & $1(20 \%)$ & 0 \\
\hline Diarrhea & $1(20 \%)$ & 0 & $1(25 \%)$ & 0 & $1(20 \%)$ & 0 \\
\hline \multicolumn{7}{|l|}{ Hepatobiliary disorders } \\
\hline $\begin{array}{l}\text { Increased } \\
\text { aminotransferase level }\end{array}$ & $1(20 \%)$ & 0 & 0 & 0 & $1(20 \%)$ & $1(20 \%)$ \\
\hline Hyperbilirubinemia & $1(20 \%)$ & $1(20 \%)$ & 0 & 0 & $1(20 \%)$ & 0 \\
\hline \multicolumn{7}{|l|}{ Electrolyte disorders } \\
\hline Hypocalcemia & $2(40 \%)$ & 0 & 0 & 0 & $1(20 \%)$ & 0 \\
\hline Hypokalemia & $1(20 \%)$ & 0 & $1(25 \%)$ & 0 & $2(40 \%)$ & $1(20 \%)$ \\
\hline Hypophosphatemia & $1(20 \%)$ & 0 & $1(25 \%)$ & 0 & $1(20 \%)$ & $1(20 \%)$ \\
\hline \multicolumn{7}{|l|}{ Miscellaneous } \\
\hline Hyperglycemia & $2(40 \%)$ & $1(20 \%)$ & $1(25 \%)$ & 0 & $2(40 \%)$ & $1(20 \%)$ \\
\hline Peripheral neuropathy & $1(20 \%)$ & 0 & $1(25 \%)$ & 0 & 0 & 0 \\
\hline Chronic kidney disease & $1(20 \%)$ & 0 & $1(25 \%)$ & 0 & 0 & 0 \\
\hline Bone fracture & 0 & 0 & $1(25 \%)$ & $1(25 \%)$ & 0 & 0 \\
\hline Rash & 0 & 0 & 0 & 0 & $1(20 \%)$ & $1(20 \%)$ \\
\hline Cough & 0 & 0 & 0 & 0 & $1(20 \%)$ & 0 \\
\hline Lymphadenitis & 0 & 0 & 0 & 0 & $1(20 \%)$ & 0 \\
\hline Hemorrhoids & $1(20 \%)$ & 0 & 0 & 0 & 0 & 0 \\
\hline
\end{tabular}

Shown are adverse events (irrespective of the relationship to the study drugs) that were reported in at least one patient.

ASCT, autologousstem cell transplant; EVTRD, exvivo regulatory T-cell depletion; IVTRD, invivo regulatory T-cell depletion.

reported to be $7.2 \pm 2.3$ days and is not influenced by age, gender, or race $^{24}$; this would suggest that a single dose should be sufficient to achieve Treg depletion within the first 30-40 days post-ASCT. Whether a second dose of basiliximab post-transplant might enhance the effect of Treg depletion might be the subject of further investigation.

The primary endpoints of this study were with respect to the kinetics of Tregs in the post-transplant period; outcomes represented secondary endpoints that were not the main focus of this study. Moreover, in light of the small sample size in this trial, the clinical outcome data must be interpreted with caution. Though this was a randomized pilot study, patients were not stratified by cytogenetic risk or by induction regimen. As such, the difference in baseline high-risk cytogenetics or induction regimens used between arms may account for differences in response.
Nevertheless, there appeared to be a signal that EVTRD led to deeper responses, which is possibly explained by an enhancement of a post-transplant antitumor response.

Treg cell depletion could serve as a non-cross-resistant therapeutic approach in the MRD-positive state and should be investigated as a platform on which other posttransplant immunotherapies could be administered to improve post-ASCT outcomes. In particular, we posit that EVTRD should be the basis for a post-ASCT combinatory immunotherapeutic approach given its reliability in efficient Treg depletion. There are already several effective uses of immunotherapies in MM, and other promising modalities are under way. Monoclonal antibodies daratumumab and elotuzumab are Food and Drug Administration (FDA)-approved for relapsed/refractory MM, with daratumumab now approved for frontline use as well. Checkpoint inhibitors targeting the PD-1/PD-L1 pathway 


\begin{tabular}{|c|c|c|c|}
\hline & $\begin{array}{l}\text { Control } \\
\text { ASCT } \\
(n=5)\end{array}$ & $\begin{array}{l}\text { IVTRD } \\
\text { ASCT } \\
(n=4)\end{array}$ & $\begin{array}{l}\text { EVTRD } \\
\text { ASCT } \\
(n=5)\end{array}$ \\
\hline $\begin{array}{l}\text { Days to neutrophil } \\
\text { engraftment, median } \\
\text { (range) }\end{array}$ & $11(10-12)$ & $11(11-13)$ & $10(10-11)$ \\
\hline $\begin{array}{l}\text { Days to platelet } \\
\text { engraftment, median } \\
\text { (range) }\end{array}$ & $10(10-11)$ & $10.5(9-12)$ & $11(10-14)$ \\
\hline $\begin{array}{l}\text { Grade } 3 / 4 \text { infections, n } \\
(\%)\end{array}$ & $2(40)$ & $2(50)$ & $4(80)$ \\
\hline $\begin{array}{l}\text { Engraftment syndrome, } \\
\mathrm{n}(\%)\end{array}$ & $0(0)$ & $0(0)$ & $1(20)$ \\
\hline $\begin{array}{l}\text { Received consolidation, } \\
\mathrm{n}(\%)\end{array}$ & $2(40)$ & $2(50)$ & $3(60)$ \\
\hline $\begin{array}{l}\text { Received maintenance, } \\
\mathrm{n}(\%)\end{array}$ & $4(80)$ & $4(100)$ & $5(100)$ \\
\hline \multicolumn{4}{|c|}{ Best response prior to ASCT, $\mathrm{n}(\%)$} \\
\hline PR & $3(60)$ & $1(25)$ & $3(60)$ \\
\hline VGPR & $1(20)$ & $1(25)$ & $1(20)$ \\
\hline $\mathrm{CR}$ & $0(0)$ & $1(25)$ & $0(0)$ \\
\hline $\mathrm{sCR}$ & $1(20)$ & $0(0)$ & $1(20)$ \\
\hline $\begin{array}{l}\text { sCR+flow MRD- } \\
\text { negative }\end{array}$ & $0(0)$ & $1(25)$ & $0(0)$ \\
\hline \multicolumn{4}{|c|}{ Best response following ASCT, n (\%) } \\
\hline PR & $2(40)$ & $0(0)$ & $0(0)$ \\
\hline VGPR & $0(0)$ & $1(25)$ & $0(0)$ \\
\hline CR & $0(0)$ & $0(0)$ & $0(0)$ \\
\hline $\mathrm{sCR}$ & $1(20)$ & $2(50)$ & $1(20)$ \\
\hline $\begin{array}{l}\text { sCR+flow MRD- } \\
\text { negative }\end{array}$ & $2(40)$ & $1(25)$ & $4(80)$ \\
\hline
\end{tabular}

ASCT, autologousstem cell transplant; $\mathrm{CR}$, complete response; EVTRD, ex vivo regulatory T-cell depletion; IVTRD, in vivo regulatory T-cell depletion; MRD, minimal residual disease (depth between $10^{-4}$ and $10^{-5}$ ); PR, partial response; sCR, stringent complete response; VGPR, very good partial response.

have been an active area of interest, particularly in the early post-transplant period; however, studies involving pembrolizumab were halted by the FDA due to an increased risk of death. ${ }^{25}$ Chimeric antigen receptor T-cell (CAR-T) therapy has shown to be effective in patients with multiply relapsed $\mathrm{MM},{ }^{26}$ and there are several competing CAR-T constructs that are currently under investigation. Recent work has exhibited the safety and efficacy of autologous New York esophageal squamous cell carcinoma-1 (NY-ESO-1)-specific peptide enhanced affinity receptor (SPEAR) T cells in the post-ASCT period (when presented by human leukocyte antigenHLA-A*02:01). ${ }^{27}$ Combination of Treg depletion and adoptive transfer of NY-ESO-1 SPEAR T cells represents another promising pairing to enhance antitumor activity post-ASCT in MM.

\section{CONCLUSIONS}

Immunotherapeutic approaches may be effective in eliminating MRD, particularly when combined with ASCT. We have shown that Treg depletion in the early post-transplant period is a feasible and safe immunotherapeutic approach in MM. Further investigation of the interplay between Treg depletion with other forms of immunotherapy in the early post-transplant period is warranted.

\section{Twitter Benjamin A Derman @bdermanmd}

Acknowledgements The authors thank the patients and their families, investigators, study coordinators, and support staff who played a role in conducting this study.

Contributors JK designed the study; BAD, YZ, RM, AJJ, TMZ, MRB, and JK collected and assembled data; BAD, YZ, AJJ, MRB, and JK analyzed and interpreted the data. BAD, MRB, and JK wrote the manuscript; and all authors participated in manuscript development and final approval.

Funding This research was supported by National Cancer Institute grant K23 CA133196.

Competing interests AJJ serves on the advisory boards of Amgen, Bristol-MyersSquibb, Celgene, Janssen, Takeda, and SkylineDX, and serves as a consultant for Abbvie. TMZ is an employee of Abbvie. MRB serves on the advisory boards of Celgene, CRISPR Therapeutics, Juno, Kite Pharma, Pharmacyclics, Seattle Genetics, and United Healthcare and serves as a consultant for Kite Pharma. JK receives honoraria from Kite, Merck, and Seattle Genetics, and receives research funding from iTeos and Merck.

Patient consent for publication Not required.

Ethics approval The protocol was approved by the institutional review board (IRB) of the University of Chicago Medical Center (IRB \#10-551-B). All patients provided written inform consent.

Provenance and peer review Not commissioned; externally peer reviewed.

Data availability statement Data are available upon reasonable request. All data relevant to the study are included in the article or uploaded as supplementary information.

Open access This is an open access article distributed in accordance with the Creative Commons Attribution Non Commercial (CC BY-NC 4.0) license, which permits others to distribute, remix, adapt, build upon this work non-commercially, and license their derivative works on different terms, provided the original work is properly cited, appropriate credit is given, any changes made indicated, and the use is non-commercial. See http://creativecommons.org/licenses/by-nc/4.0/.

\section{ORCID iD}

Benjamin A Derman http://orcid.org/0000-0002-4070-1819

\section{REFERENCES}

1 Attal M, Lauwers-Cances V, Hulin C, et al. Lenalidomide, bortezomib, and dexamethasone with transplantation for myeloma. N Engl J Med 2017;376:1311-20.

2 Attal M, Harousseau J-L, Stoppa A-M, et al. A prospective, randomized trial of autologous bone marrow transplantation and chemotherapy in multiple myeloma. N Engl J Med 1996;335:91-7.

3 Child JA, Morgan GJ, Davies FE, et al. High-Dose chemotherapy with hematopoietic stem-cell rescue for multiple myeloma. $N$ Engl J Med 2003;348:1875-83.

4 Fermand J-P, Katsahian S, Divine M, et al. High-Dose therapy and autologous blood stem-cell transplantation compared with conventional treatment in myeloma patients aged 55 to 65 years: long-term results of a randomized control trial from the group Myelome-Autogreffe. J Clin Oncol 2005;23:9227-33.

5 Barlogie B, Kyle RA, Anderson KC, et al. Standard chemotherapy compared with high-dose chemoradiotherapy for multiple myeloma: final results of phase III us intergroup trial S9321. J Clin Oncol 2006;24:929-36.

6 Bladé Jet al. High-Dose therapy intensification compared with continued standard chemotherapy in multiple myeloma patients 
responding to the initial chemotherapy: long-term results from a prospective randomized trial from the Spanish cooperative group PETHEMA. Blood 2005;106:3755-9.

7 Palumbo Aet al. Intermediate-dose melphalan improves survival of myeloma patients aged 50 to 70 : results of a randomized controlled trial. Blood 2004;104:3052-7.

8 Kline J, Subbiah S, Lazarus HM, et al. Autologous graft-versus-host disease: harnessing anti-tumor immunity through impaired selftolerance. Bone Marrow Transplant 2008;41:505-13.

9 D'Arena G, Vitale C, Coscia M, et al. Regulatory T cells and their prognostic relevance in hematologic malignancies. J Immunol Res 2017;2017.

10 Ganeshan P, Gupta R, Hakim M, et al. Reconstitution of regulatory T cells after autologous transplantation in multiple myeloma. Int $J$ Hematol 2011;94:578-9.

11 Batorov EV, Tikhonova MA, Pronkina NV, et al. Increased circulating $\mathrm{CD}^{+} \mathrm{FOXP}^{+} \mathrm{T}$ cells associate with early relapse following autologous hematopoietic stem cell transplantation in multiple myeloma patients. Oncotarget 2018;9:27305-17.

12 Perez-Garcia A, Cabezudo E, Lopez-Jimenez J, et al. Immune reconstitution of regulatory T-cells following autologous hematopoietic stem cell transplantation. Biology of Blood and Marrow Transplantation 2009;15.

13 Shimizu J, Yamazaki S, Sakaguchi S. Induction of tumor immunity by removing CD25+CD4+ T cells: a common basis between tumor immunity and autoimmunity. J Immunol Baltim Md 1999;1950:5211-8.

14 Nishikawa H, Sakaguchi S. Regulatory T cells in cancer immunotherapy. Curr Opin Immunol 2014;27:1-7.

15 Kawano Y, Zavidij O, Park J, et al. Blocking IFNAR1 inhibits multiple myeloma-driven Treg expansion and immunosuppression. J Clin Invest 2018;128:2487-99.

16 Muthu Raja KR, Rihova L, Zahradova L, et al. Increased T regulatory cells are associated with adverse clinical features and predict progression in multiple myeloma. PLoS One 2012;7:e47077.
17 Kawano Y, Moschetta M, Kokubun K, et al. Characterization of the role of regulatory T cells (Tregs) in inducing progression of multiple myeloma. Blood 2015;126:502

18 Wang J-nuo, Cao X-xin, Zhao A-lin, et al. Increased activated regulatory $T$ cell subsets and aging Treg-like cells in multiple myeloma and monoclonal gammopathy of undetermined significance: a case control study. Cancer Cell Int 2018;18:187.

19 Sakaguchi S. Naturally arising Foxp3-expressing CD25+CD4+ regulatory $\mathrm{T}$ cells in immunological tolerance to self and non-self. Nat Immunol 2005;6:345-52.

20 Zheng Y, Rudensky AY. Foxp3 in control of the regulatory T cell lineage. Nat Immunol 2007;8:457-62.

21 Kumar S, Paiva B, Anderson KC, et al. International myeloma Working group consensus criteria for response and minimal residual disease assessment in multiple myeloma. Lancet Oncol 2016;17:e328-46.

$22 \mathrm{Ni} \mathrm{X}$, Langridge T, Duvic M. Depletion of regulatory T cells by targeting CC chemokine receptor type 4 with mogamulizumab. Oncoimmunology 2015;4:e1011524.

$23 \mathrm{Kim}$ YH, Bagot M, Pinter-Brown L, et al. Mogamulizumab versus vorinostat in previously treated cutaneous T-cell lymphoma (MAVORIC): an international, open-label, randomised, controlled phase 3 trial. Lancet Oncol 2018;19:1192-204.

24 Basiliximab, Novartis Pharmaceutical Corp - Package Insert. Available: https://www.accessdata.fda.gov/drugsatfda_docs/label/ 2003/basnov010203lb.htm [Accessed 7 Mar 2019].

25 Food and Drug Administration. Fda alerts healthcare professionals and oncology clinical Investigators about two clinical trials on hold evaluating KEYTRUDA® (pembrolizumab) in patients with multiple myeloma. Available: https://www.fda.gov/Drugs/DrugSafety/ ucm574305.htm [Accessed 31 Mar 2019].

26 Raje N, Berdeja J, Lin Y, et al. Anti-BCMA CAR T-cell therapy bb2121 in relapsed or refractory multiple myeloma. N Engl J Med 2019;380:1726-37.

27 Stadtmauer EA, Faitg TH, Lowther DE, et al. Long-term safety and activity of NY-ESO-1 spear T cells after autologous stem cell transplant for myeloma. Blood Adv 2019;3:2022-34. 